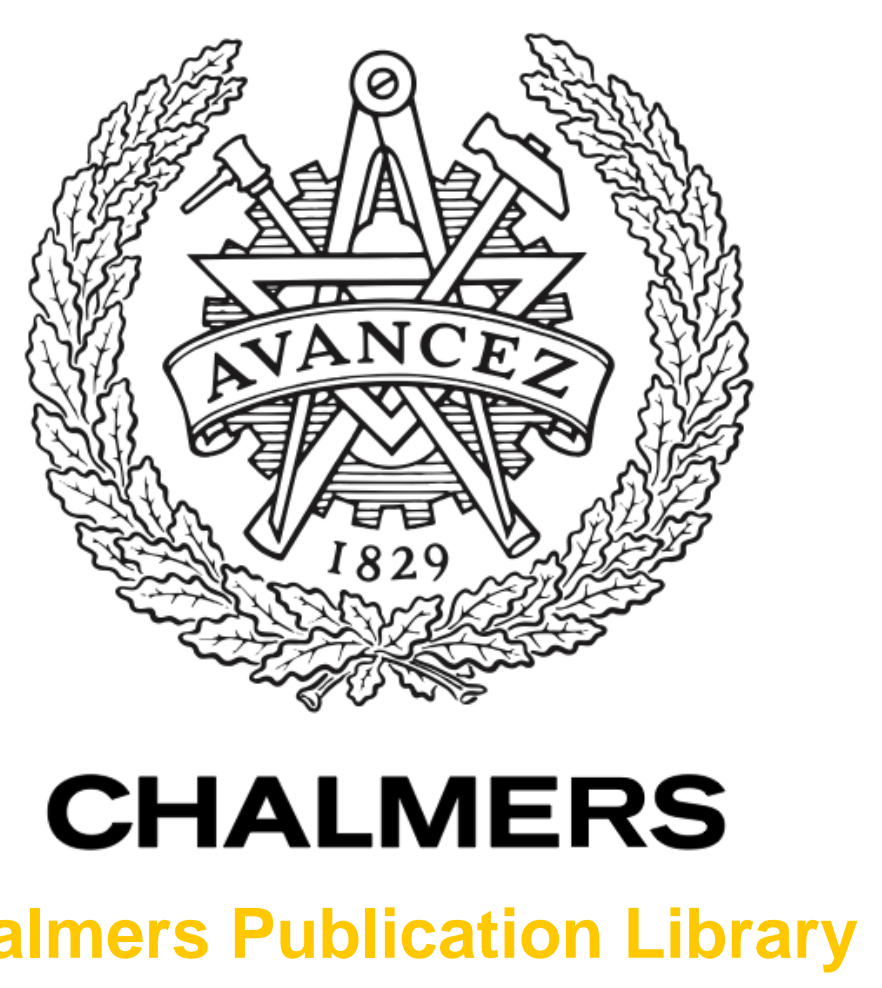

\title{
Improving the European Commission's analytical base for designing instrument mixes in the energy sector: Market failures versus system weaknesses
}

This document has been downloaded from Chalmers Publication Library (CPL). It is the author's version of a work that was accepted for publication in:

\section{Energy Research and Social Science (ISSN: 2214-6296)}

Citation for the published paper:

Jacobsson, S. ; Bergek, A. ; Sandén, B. (2017) "Improving the European Commission's analytical base for designing instrument mixes in the energy sector: Market failures versus system weaknesses". Energy Research and Social Science

http://dx.doi.org/10.1016/j.erss.2017.09.009

Downloaded from: http://publications.lib.chalmers.se/publication/252451

Notice: Changes introduced as a result of publishing processes such as copy-editing and formatting may not be reflected in this document. For a definitive version of this work, please refer to the published source. Please note that access to the published version might require a subscription. 


\title{
Improving the EU Commission's analytical base for designing instrument mixes in the energy sector: market failures versus system weaknesses
}

\author{
Staffan Jacobsson, Anna Bergek*, Björn Sandén \\ Department of Technology Management and Economics, Chalmers University of Technology, \\ SE-41296 Göteborg, Sweden. Email: staffan.jacobsson@chalmers.se; \\ anna.bergek@chalmers.se; bjorn.sanden@chalmers.se
}

*Corresponding author

Keywords: instrument mix; transformation; innovation system

\begin{abstract}
To limit global warming to 1.5-2 degrees, EU needs to eliminate emissions of $\mathrm{CO}_{2}$ equivalents over the next decades, which necessitates that a range of new technologies develop, mature and diffuse on a massive scale. To create conditions for this, effective instrument mixes have to be designed and implemented. However, the choice of such mixes depends on the analytical rationale for policy intervention. The purpose of this paper is, therefore, to scrutinize the analytical base of the EU Commission, contrast it with the work of classical economists and recent innovation scholars, and draw lessons for how effective mixes of policy instruments may be identified. We show that the Commission's focus on market failures, static efficiency and technology neutrality does not cover all possible obstacles and leads it to neglect the centrality of dynamic efficiency and the structural build-up of innovation systems around new technologies.
\end{abstract}

\section{Introduction}

At the current rate of $\mathrm{CO}_{2}$ emission reduction, it would take over 70 years for the European Union (EU) to be free from carbon emissions. In order to meet the goal of the Paris agreement, EU policy makers need to make sure that major transformations take place over the next decades, or EU member states will either continue to burden next generations with costs of climate change or be forced to limit economic growth to one that is consistent with the desired reductions, with consequences for employment and welfare [1].

Realising a full decarbonisation involves large-scale, transformative changes in the energy and transport systems as well as in agriculture and manufacturing of, e.g., steel and cement

(C) 2017. This manuscript version is made available under the CC-BY-NC-ND 4.0 license http://creativecommons.org/licenses/by-nc-nd/4.0/ 
[2]. In the electricity sector a complete substitution of fossil fuels by 2050 may entail adding about 2,400 TWh of new annual renewable electricity generating capacity over a period of roughly 35 years. ${ }^{1}$ This would require that the annual increase in renewable supply in the period of 2011-2014, which so far has involved the greatest increase in EU history, not only has to be maintained but actually increased by more than $25 \%$ [4].

Large-scale transformations constitute a formidable challenge for policy-makers, who need to design and implement a portfolio of policy instruments that together can handle a wide variety of obstacles to the development and diffusion of the technologies required for transforming many industries in only a few decades. In recent theorizing about innovation and transition policy, it has been emphasized that the choice and calibration of such “instrument mixes” are dependent both on the underlying policy strategy and on the policy processes through which strategies and instrument mixes evolve [5, 6]. In addition, it has been acknowledged that instrument mixes have to be compatible with the dominant governance modes of the concerned sector, including what kind of goals policy makers typically set up and what instruments they prefer $[6,7]$. In the same vein, it has been suggested that the evaluation of policy mixes should include the underlying policy rationale [8]. This is the focus of this paper. The overall argument is that the analytical rationale guiding policy makers, e.g. market failures or systemic weaknesses, has a direct influence on what problems policy makers acknowledge and what instruments they see as appropriate for solving those problems.

The European (EU) Commission explicitly advocates market failures and static costeffectiveness as guides to the selection of policy instruments to support the development and diffusion of renewable energy technologies, in line with a static equilibrium approach [e.g. 9]. In the following, we will show that there are weaknesses in the Commission's approach, which may lead to ineffective instrument mixes, threatening our ability to meet the goals of the Paris agreement. It is, therefore, important to compare the EU approach with alternative frameworks guiding interventions.

Indeed, technical change and industrial transformation has been subject of research ever since the classical economists, e.g. Smith [10] and Marshall [11]. Their focus on industrial

\footnotetext{
${ }^{1}$ Assuming 1) that electricity demand increases by 0.5\% p.a. (630 TWh in total 2050) (which may be a gross underestimation [3]) and 2) that current nuclear power stations are closed down and new nuclear power stations supply 500 TWh by 2050 [cf. 4].
} 
dynamics leads to an awareness that large-scale transformative change necessitates structural changes in the capital goods industry. Such changes are complex and uncertain in their outcomes, but may lead to learning processes in the value chain and, eventually, large-scale diffusion of technologies that replace incumbent technologies. Building in part on their work, more recent scholars developed innovation system approaches aiming to provide an analytical base for identifying mixes of policy instruments to foster industrial dynamics. Their focus on system weaknesses (instead of market failures) that obstruct dynamics, motivates an analysis of these as alternative (or complement) to the current EU approach. The purpose of this paper is, therefore, to scrutinize the analytical base of the EU Commission, contrast it with the work of classical economists and recent innovation scholars, and draw lessons for how effective mixes of policy instruments may be identified.

Section 2 introduces the analytical elements used by the EU Commission in its static costeffectiveness approach. Section 3 discusses three classical economists' understanding of the dynamics of technical change and industrial development and how it relates to the static approach of the Commission. Section 4 proceeds to outline the innovation system dynamics approach, as an alternative framework. This generates a broader instrument mix than the EU Commission's approach, a greater focus on dynamic rather than static efficiency and a stronger emphasis on technology-specific instrument mixes. Section 5 contains an illustrative case study in which the innovation system and market failure approaches are applied to propose (partly different) instrument mixes for offshore wind power in Sweden. Finally, section 6 draws lessons for policy in the EU and points to a key area for further research.

\section{The analytical elements of the EU Commission approach}

The EU Commission's approach to renewable energy policy is based mainly on analytical elements from static equilibrium theory, which is concerned with an efficient allocation of resources and related welfare issues. A major characteristic of this perspective is that it ignores the dynamics of technological change and industrial development. The economic system is instead seen to be in a steady state equilibrium characterised by decreasing returns (rising marginal costs). Firms and other actors are assumed to be perfectly informed about all relevant factors and capable of instantly arriving at an optimal choice [12]. Additionally, there are no uncertainties about the future and prices are set so that all markets are in equilibrium. 
With some additional assumptions, prices then reflect consumers’ marginal valuations and producers' marginal costs [13].

In this approach, government interventions are justified if markets fail to meet these conditions, resulting in an inefficient allocation of resources. This policy rationale is explicitly referred to in the EU Guidelines on state aid for environmental protection and energy 20142020 (henceforth "the Guidelines”) [14, p. 13]: “Whereas it is generally accepted that competitive markets tend to bring about efficient results in terms of prices, output and use of resources, in the presence of market failures state intervention may improve the efficient functioning of markets.” Member states are directed to specify the market failures that motivate a proposed policy intervention. These failures are of various kinds:

- Positive externalities imply that an activity (e.g. R\&D) by one actor benefits other actors without charge, i.e. the marginal social revenue of an economic activity is higher than marginal private revenue. Since the full value of an activity cannot be appropriated, actors will underinvest compared to the optimal level.

- Negative externalities refer to costs that accrue to other actors without these being compensated, i.e. marginal social costs are higher than marginal private costs. Since these costs are not reflected in prices they might lead to overinvestment in activities that benefit individual actors, but are undesirable from a social point of view.

- An effective functioning of markets assumes that actors are perfectly informed about all relevant factors and capable of instantly arriving at an optimal choice. Information asymmetries refer to a situation when the assumption of actors having full (and equal) information does not hold. This makes it difficult for actors to assess the quality of goods and services and observe other actors' knowledge and actions, which results in non-equilibrium prices and inefficient transactions [15].

- Coordination failures imply that if there are interdependencies among firms but these do not coordinate their investments, optimal decisions are not taken. For instance, car manufacturers and biofuel firms may have to coordinate their decisions to develop engines and new types of fuel.

- Increasing returns in the form of economies of scale for individual firms imply that the marginal unit cost decreases with increasing production volumes. This creates entry barriers and can, therefore, lead to a monopolistic market structure and 
imperfect competition. Moreover, if increasing returns prevail, marginal cost pricing is unlikely to take place.

- Capital market failures may occur due to different propensities to take risks between individual firms and society at large as well as to different private and social discount rates. Capital market failures lead to underinvestment in technologies for which risks are high and for which the learning process is so long that the time required to break even is beyond the planning horizon of the individual firm whereas it is not beyond the horizon of the state [16]. ${ }^{2}$

With regard to appropriate instruments to remedy market failures in the energy sector, the EU Commission's approach is based on two main components: 'technology push' and 'market pull' [18]. The technology push component mainly consists of various types of (financial) support to R\&D and innovation, derived from the FP7 and Horizon 2020 programs and administrated through the so-called Strategic Energy Technology (SET) Plan [18]. ${ }^{3}$ While the underlying rationale of the SET Plan is not explicit, key documents emphasize the general importance of "tackling the barriers that hold back private investment" (e.g. through improving the patenting system) [18] and overcoming the "valley of death" between demonstration and commercialization (e.g. through loans and loan guarantees for first-of-akind commercial-scale industrial demonstration projects) [19], which indicates that the focus is on handling positive externalities and capital market failures. Considering that the SET Plan includes technology-specific RD\&D agendas, we assume that there is some awareness that these market failures might differ between technologies.

With regard to 'market pull', the EU Commission [14] mainly discusses the negative environmental externalities associated with fossil fuels and puts forward regulation and market-based instruments, in particular the EU ETS and $\mathrm{CO}_{2}$ taxes, as the most important instruments to remedy this market failure. ${ }^{4}$ However, since it presumes that these instruments are not able to fully correct the negative environmental externalities associated with fossil fuels, it allows its member states to complement them with different forms of aids to renewable energy [14]. Such aid can come in the form of investment or operating aids, where

\footnotetext{
${ }^{2}$ See Gawell et al. [17] for a more detailed explanation, pointing to underlying reasons for differences between social and private discount rates.

${ }^{3}$ The EU only contributes about $10 \%$ of the funding of the SET Plan [2].

${ }^{4}$ It also acknowledges that soft instruments, such as voluntary eco-labels, can play an important role [14].
} 
the former imply grants to cover part of the investment cost of new plants and the latter production premia (e.g. feed-in premia or green certificates [20]) paid in addition to the wholesale price for electricity to compensate for the higher production costs of renewables.

A basic premise is that when such state aids are used, care should be taken to choose the instruments that have the least distorting effects on trade and competition. To the Commission, this implies that market formation policies (aids) should be technology-neutral. Already in 1999, it argued for a deployment policy leading to static cost-effectiveness, i.e. “...that electricity is generated and sold at minimum cost” [21, p. 15], and it also made repeated attempts to ban 'German-style' technology-specific feed-in tariffs [22]. In line with this, the Guidelines mandate member states to use competitive bidding processes, open to all generators producing electricity from renewables [23], when granting support [14, 20, 23]. In such a bidding process, producers of electricity from renewables (e.g. on- and offshore wind power, solar PV and biomass CHP) compete for contracts to deliver certain amounts of renewable electricity and the bids of the winning producers determine the support levels for each contract. In contrast to RD\&D support, competitive bidding can only be restricted to specific technologies if it is clear that it would lead to a suboptimal result [14, 20, 23]. Some of the eligible exceptions are new/innovative technologies and small installations [14, 23].

Apart from acknowledging the need to combine R\&D support with market deployment instruments and to complement the EU ETS and CO2 taxes with aid to renewables, there is not much discussion about instrument mixes in the EU policy documents referred to above. In line with traditional advice from static equilibrium theorists, who have tended to advocate the use of one policy to achieve a specific policy target [24], the EU Commission [14] states that additional instruments may only be directed at market failures that remain unaddressed by the instruments that are already in place and also cautions that different measures to remedy the same or different market failures can counteract each other. This, in our opinion, reflects a rather narrow perspective on the design of instrument mixes.

It should, however, be noted that static equilibrium theory in principle allows for a broader view on the instrument mix than that of the EU Commission. First, there is an understanding in the literature that the one-target-one-instrument approach only applies to the extent that policy problems are rather simple, and that a mix of different instruments is required to handle more complicated policy problems [7, 25]. In particular, when there are multiple market 
failures, it may be suboptimal to address only one of these and a mix of instruments that address all failures simultaneously might be needed [24, 26]. A mix may, for example, combine policy instruments that a) internalize external costs (e.g. a carbon tax), b) reduce risks and extend the time horizon of investors (e.g. financial instruments that absorbs risks in general) and c) encourage knowledge development that gives rise to positive externalities (e.g. R\&D subsidies). Second, some equilibrium theorists acknowledge that the degree and relevance of individual market failures differ between technologies [cf. 27]. For example, renewable electricity technologies are heterogeneous with regard to external costs and benefits as well as investment risks, and such heterogeneity influences externalities and capital market failures respectively [17]. This opens up for technology differentiation, not only in RD\&D funding but also in other parts of the instrument mix.

In spite of these developments, keeping to static equilibrium theory as a guide to policy may not provide adequate support for policy makers as far as transformative change is concerned. Marshall [11, pp. 381-382], who writes a great deal on static equilibrium theory and decreasing returns, recognizes that it "is only an introduction to economic studies; and it is barely even an introduction to the study of the progress and development of industries which show a tendency to increasing returns.” To understand the latter phenomenon better, we turn to the classical economists.

\section{Our heritage from the classical economists}

Technical change and industrial dynamics has been discussed since Smith [10] and other classical economists - most notably Karl Marx and John Marshall - have contributed to our understanding of these phenomena, pointing in particular to the central role of the capital goods industry and identifying a set of processes that define the nature of the policy challenge related to transformative change, which, consequently, are of relevance for instrument mixes aimed at enabling such change. This section first specifies our intellectual heritage from the classical economists and then reflects on how it relates to the EU Commission's approach to transformative change.

Adam Smith had a remarkably complete picture of the sources of technical change, including what today would be called the capital goods industry and university $R \& D$ [10, p. 115]: 
"All the improvements in machinery...have by no means been the inventions of those who had occasion to use the machines. Many improvements have been made by the ingenuity of the makers of machines, when to make them have become the business of a peculiar trade; and some by those who are called philosophers or men of speculation, whose trade is not to do anything, but to observe everything; and who....are often capable of combining together the power of the most distant and dissimilar objects. In the progress of society, philosophy or speculation becomes, like every other employment, the principal or sole trade... of a particular class of citizens.”

In the Early Draft of the Wealth of Nations, Smith elaborates further on the innovation process, using the example of a grinding mill [28, p. 338]:

“...different improvements were probably not all of them inventions of one man, but the successive discoveries of time and experience and the ingenuity of many different artists.”

Realising the importance of learning processes, Smith emphasized the gradual and timedependent nature of technical change, where the experience of either producing or using a machine resulted in a series of major and minor changes to it. Similarly, Marshall [11, p. 265] discussed the importance of increasing returns for improvements of production processes, i.e. in terms of a relationship between (increasing) size of aggregate production and (reduced) cost of production:

“...the part which nature plays in production shows a tendency to diminishing return, the part which man plays shows a tendency to increasing return. The law of increasing return may be worded thus: an increase of labour and capital leads generally to improved organisation, which increases the efficiency of the work of labour and capital.”

He cautions though that "the tendency to increasing returns does not act quickly", that is, the time-scale may be long [11, p. 377].

Thus, in contrast to static equilibrium theory, which treats increasing returns as a source of market failure, Smith and Marshall argue that in the context of technical change and industrial development, increasing returns are both to be expected and desired. As Marshall [11, p. 381382] explains:

“...we expect short-period supply price to increase with increasing output. But we would also expect a gradual increase in demand to increase gradually the size and efficiency of this representative firm; and to increase the economies both internal and external which are at its disposal. That is to say, when making lists of supply prices ... for long periods in these industries, we set down a diminished supply price against an increased amount of the flow of the goods." 
In addition to the insight that technical change is dependent on learning and increasing returns on the supply side, an important heritage from the classical economists is that they related these processes to the interlinked processes of division of labour and market formation. In The Wealth of Nations, Smith [10, p.109] argued that a fundamental cause of increasing returns is the process of division of labour:

"The greatest improvements in the productive powers of labour, and the greater part of the skill, dexterity and judgement with which it is anywhere directed, or applied, seems to have been the effects of the division of labour."

While in his famous example of the pin-making factory, Smith's focus is on the organization of production and learning by the specialized worker, he also recognized that the principle of division of labour extends from this detailed, organization-level division to a social division between and within different industries. This was emphasised by Marx [29, p. 361] in his analysis of "Modern Industry”.

"As inventions increased in number, and the demand for the newly discovered machines grew larger, the machine-making industry split up, more and more, into numerous independent branches, and division of labour in these manufactures was more and more developed. Here then, we see ...the immediate technical foundation of Modern Industry”.

Increasing return is, thus, not necessarily reflected in the size of individual firms, or even a particular industry. Therefore, Young [30, p. 539] noted that what “...is required is that industrial operations be seen as an interrelated whole”.

In such an “interrelated whole”, Marshall distinguished between internal and external economies and argued that as aggregate production increases, the external economies to which a firm has access will increase. These are of many kinds [11, p. 225]:

"the mysteries of the trade become no mysteries; but are as it were in the air... inventions and improvements in machinery... have their merits promptly discussed: if one man starts a new idea, it is taken up by others and combined with suggestions of their own; and thus it becomes the source of further new ideas...subsidiary trades grow up...economic use of expensive machinery can... be attained in a district where there is a large aggregate production... and a localized industry gains great advantage from the fact that it offers a constant market for skill.”

Hence, Marshall identified what could be interpreted as knowledge diffusion and inspiration to create new combinations (innovations in Schumpeter's terms), access to firms in the supply 
chain, use of specialised machinery and access to skilled labour as ways in which external economies benefit firms in industries with a high aggregate production.

The gradual and time-dependent nature of technical change, which relies on a social division of labour generating increasing returns, depends though on the formation of markets. As Smith [10, p. 122] explains:

"As it is the power of exchanging that gives occasion to the division of labour, so the extent of this division must always be limited by the extent ... of the market".

In conclusion, our intellectual heritage from the classical economists is that they see industrial dynamics as a process in which a social division of labour is formed generating specialised industries, including a capital goods industry, and new scientific fields. Through this division of labour, learning is enabled which leads to increasing returns. Industrial dynamics is also characterised by a multitude of external economies (in addition to internal) and a long timescale. Finally, the whole process is strongly dependent on market formation which means that technical change is not linear.

This heritage contrasts with the EU Commission's application of static equilibrium theory, with its focus on short-term efficient allocation of resources. First, several of the phenomena seen as leading to market failures are inherent features of transformative change processes according to classical economists. In addition to the central role of increasing returns, this applies to information asymmetries in dynamic systems, which as Metcalfe [31, p. 26] argues "can scarcely be termed market imperfections when they are necessary conditions for any technical change to occur in the market”. Asymmetric information is, therefore, an essential element in the working of a competitive and dynamic capitalist economy where innovative firms search for new business opportunities and develop new technologies and strategies based on ideas and knowledge that other firms do not share [15].

Also, positive externalities abound in dynamic systems, but these do not necessarily lead to a stunted development. With respect to information flows, Metcalfe [32, p. 56] argues that "there is no reason why an alert firm should not gain more than it loses from the unplanned flow of information and so enrich its innovative capacity”. Carlsson and Jacobsson [33, p. 271] argue in a similar way that positive externalities tends to prevent other failures by the existence of reciprocal externalities: “... the reciprocal flow of information may well result in 
the blending of visions (technological expectations) of the future among various actors. Sharing the same vision may then lead to a reduction in perceived risk and a quasicoordination of investment between formally independent actors.”

Moreover, externalities can be both development- and deployment-related [34, 35], for example:

- early investments in a new technology that enable a division of labour in the form of establishment of specialized suppliers (e.g. component suppliers and intermediaries) and realisation of increasing returns benefit subsequent investors [36, 37].

- investments that strengthen the legitimacy of a new technology may facilitate the mobilization of capital for other firms [38].

- investments by firms in new applications may influence the search for business opportunities by other firms [39].

This implies that in a dynamic system (rather than a static equilibrium), positive externalities are not primarily the effect of poorly appropriated technical knowledge, but may result from a range of investments by firms, some which lead to reciprocal external economies. The key challenge is, therefore, to ensure that markets are formed to stimulate the generation of positive externalities, although a weak appropriation of benefits may, of course, also constitute a problem.

These inherent features of transformative change processes imply a fundamental difference in perspectives with regard to policy rationales; whereas a static equilibrium type of policy is focused on compensating for market failures, a classical economist type of policy could very well aim at strengthening the phenomena that may lead to such 'failures'.

Second, the classical economists emphasize the centrality of increasing returns for reaching the goal of transformative change. This implies that the policy issue is not to select the best technology "from the shelf” but simultaneously foster a range of technologies [40] and associated industries by forming markets which allow increasing returns to be realized, putting technologies “on the shelf”. It is, thus, dynamic efficiency, i.e. the impact of deployment instruments on innovation and cost reduction [25, 35, 41, 42], rather than static 
efficiency which should guide policy. Static efficiency may, in contrast, be in conflict with effectiveness in the sense of ability to achieve policy targets [35].

To an extent, dynamic efficiency as a guide to policy is reflected in the EU Commission's Guidelines, which (as mentioned above) open up the possibility to limit competitive bidding processes to specific technologies, e.g. tidal power, in consideration of “... the longer-term potential of a given new and innovative technology" or other circumstances that might lead to suboptimal results of an open process [14, p. 26]. ${ }^{5}$ While this inclusion is a step forward, the scope for such technology-specific tenders is limited. In the general regulations on state aid, the EU Commission [23, p. 27] defines a new and innovative technology as "a new and unproven technology compared to the state of the art in the industry, which carries a risk of technological or industrial failure and is not an optimisation or scaling up of an existing technology". It also states that technology-specific aid "shall not be granted for more than $5 \%$ of the planned new electricity capacity from renewable energy sources per year in total” [23, article 42: 4].

Even though it is reasonable to restrict this kind of support to immature technologies, these limitations risk playing down the size of markets and time needed for fostering new and innovative supply chains that enable sufficient increasing returns to be realized. This risk is particularly relevant for the energy sector, which produces homogenous products that do not provide users with novel utilities motivating an early market formation, unlike for investment goods such as industrial robots or consumer goods such as mobile phones. The strategic technology [43] offshore wind power may provide an illustration. A five-percent limit would exclude offshore wind power from being subject to a technology-specific bidding process, since its share of the planned new capacity was already larger than that when the EU Commission's Guidelines were published. ${ }^{6}$ However, the industry was, and is still, vulnerable and to remove the technology-specific support systems would risk leading to failure for firms in the entire value chain, threatening our ability to supply the necessary volumes of renewable electricity production.

\footnotetext{
${ }^{5}$ The working document accompanying the Guidelines explicitly connects this option to dynamic efficiency [20].

${ }^{6}$ The added supply of electricity from renewable energy sources was 90 TWh in 2013 and off-shore wind power accounted for about $6 \%$ of these. For 2014, the figures were 41 TWh and 13\% respectively. [4, 44]
} 


\section{Innovation system dynamics as guide to policy makers}

Considering these weaknesses in the EU approach, we turn to parts of the innovation system literature to find an alternative or complement to it. We first introduce the notion of innovation systems and point to aspects of its heritage from classical economists before we discuss how this framework can be useful for policy purposes by helping to identify obstacles to transformation processes.

The innovation system approach emphasizes the collective and institutional aspects of the innovation process and, as Dodgson et al. [45, p. 1146] put it, “... the dynamic, emergent, and evolving nature of systems.” It suggests that the development, diffusion and use of new knowledge and technologies is the outcome of actions and interactions by private and public actors working under a particular national, regional, sectoral or technological institutional infrastructure [46-50]. It is this set of actors, the political and learning networks they form and the institutions that guide their actions that we call an innovation system.

Innovation systems are characterized by two types of dynamic processes: structural and functional. Structural dynamics concern the system's set-up in terms of actors, networks and institutions. Especially in an early phase of system development, structural build-up in terms of entry of firms and other organisations in the entire value chain, network formation and institutional change are key aspects of the innovation process [51]. This is a cumulative process, in which system elements evolve, cluster and eventually reach a critical mass [52]. The intellectual heritage from the classical economists, with their focus on structural dynamics through a social division of labour generating specialised industries, including a capital goods industry, and new scientific fields is here clear. Indeed, Metcalfe [53, p. 117] observes that "In all but name, Marshall can be said to have described elements of an innovation system”.

It should be noted that although the IS approach focuses on collective aspects, it has a clear understanding of the characteristics of actor-level strategies and behaviour in relation to technical and industrial change, building on research in strategic and innovation management. This literature has noted that the main reason why firms exhibit different behaviour in response to technological opportunities and threats is not information asymmetries or bounded rationality (as often assumed by static equilibrium theorists), but asymmetric capabilities and 
associated bounded visions [54]. Firms operate with different knowledge bases and under different assumptions concerning technology and future markets and this variation is due to long historical processes where learning processes are local, cumulative and path-dependent [55]. In that process, capabilities and problem-solving strategies are formed which influence cognition and internal power structures which, taken jointly, may help explain organisational inertia [56, 57]. This inertia may lead firms to 'filter away' signals from the environment on new technological opportunities and remain focussed on dominant technologies.

Such actor-level inertia can be further strengthened by the innovation system of which the firms (and other actors) form a part. As emphasized by Lundvall [58] and the growing literature on open innovation [59], knowledge and technology is generated in a process of interactive learning within networks of firms, where trust is an essential element. Moreover, an actor's behaviour is not only influenced by its task environment (including its cooperative and competitive relationships with other actors), but also by its institutional environment (including norms, regulations and cognitive frames), and different institutional structures lead to differences in (economic) behaviour [60]. Hence, actor-level inertia may be influenced by both networks and institutions.

Functional dynamics concern processes influencing the development, diffusion and utilization of new products and processes within the system. These include, for instance, development and diffusion of formal knowledge (e.g. through R\&D), trial-and-error learning and uncertainty reduction through experiments, market formation, provision of incentives that guide the direction in which actors deploy their resources, mobilization of financial, human and physical resources, the development of social acceptance (i.e. legitimacy) and the development of positive externalities [cf. 61].

Here as well, the heritage from the classics is strong. In addition to the emphasis on positive externalities, innovation is seen as non-linear, i.e. it is not seen as "flowing smoothly down a one-way street” [62, p. 285], where research leads to development, development to production and production to marketing and R\&D is sufficient for driving innovation and cost-reductions. Instead, the IS approach acknowledges the centrality of market formation for the innovation process and in realizing increasing returns. Indeed, increasing returns are one of the most important outcomes of innovation system dynamics, as reflected in downward-sloping learning curves in the production and use of technologies. 
The structural and functional dynamics of innovation systems influence each other and the innovation process in various ways [61, 63]. New entrants bring resources into the IS, which can be used to develop knowledge through $R \& D$ or trial-and-error experimentation. They can also help legitimize a new technology if they have a good name or devotes resources to promote legitimacy. Groups of actors can form political networks that influence policymakers to develop and align regulations and other formal institutions to the needs of the new technology. This might lead to the formation of markets, which in turn might induce external firms to change their strategies and diversify into the system. This mobilizes new resources in terms of both human and financial capital to be used for, e.g., the development of more knowledge or market formation activities. In this way, the structure of the system builds up and its functionality improves over time in an interactive process characterized by feedback between system structuration and key innovation processes.

System dynamics are also influenced by the context of the focal system and can influence it in return [64]. For instance, the development of complementary technologies, e.g. in energy storage, may raise expectations of growing markets for intermittent renewable energy technologies as may a growing awareness of the climate challenge with an associated legitimating discourse and legislative changes. In the other direction, market formation and growth or strengthened legitimacy of an emerging IS (perhaps as a consequence of persuasive political networks), can influence actors in contextual systems to enter. An innovation system, thus, “... moves under the influence of outside pushes and pulls and the momentum of its own internal processes” [cf. 65, p. 18].

As also emphasised by Marshall [11], the emergence and further development of an innovation system is characterized by long time-scales. The formative phase, in which a capital goods industry emerges and develops the capacity to provide a new technology with reasonable price/performance, often takes a couple of decades [51, 66]. An additional two to three decades may be required to increase the production capacity, to benefit from further increasing returns and deploy the technology until the market is saturated.

The outcomes of this complex process are not always in line with societal expectations. There are plenty of uncertainties, for example in terms of a need for secondary innovations to improve an initially poor price/performance, evolution of competing designs and 
complementary technologies, improvements in incumbent technologies, unpredictable and gradual unfolding of markets and uncertainties arising from political changes and associated alterations in regulations and norms. Indeed, an innovation system might achieve too little innovation in general or with regard to certain types of products or processes [67], as compared with what is considered appropriate by relevant stakeholders, or it might require a change in directions in order to cope with current societal challenges [68]. Under certain circumstances such problems could be severe enough to justify policy interventions and the innovation system approach was originally developed with the explicit aim to guide policymakers in designing policy for fostering innovation [69].

While some of the IS literature recognizes that market failures describe important features of the resource allocation process in an economy with decentralized decision-making and, thus, captures empirical phenomena of importance for technical change processes [33, 45], the main rationale for and guide to policy intervention in the IS approach is the existence of system weaknesses (or failures) [70]. As innovation system dynamics is shaped through interactions between system elements and contextual influences, it follows that the characteristics of these may not always be supportive. Policy interventions could then be justified and interventions be guided towards specific system weaknesses in the structural elements of a system, such as poorly aligned institutions, absent or weak networks or actors that are locked into incumbent technologies [e.g. 71, 72, 73]. ${ }^{7}$ Moreover, given that dynamics is influenced by interactions with contextual elements, system weaknesses can also be found outside a focal system [36, 52]. For instance, actors in the capital market may lack the required knowledge to assess investment opportunities in novel technologies and incumbent firms may act politically to delegitimize new technologies.

System weaknesses cover a broad set of obstacles to innovation and transformative change, as demonstrated by Jacobsson and Bergek [76] and Wieczorek and Hekkert [77]. These justify policy intervention even in the absence of traditional market failures. For example, as actorlevel inertia is not included among the standard market failures, policy makers can fail to

\footnotetext{
${ }^{7}$ In contrast to market failures, system weaknesses do not refer to deviations from an optimum but to factors and mechanisms impeding the structural and functional dynamics of a particular innovation system [63]. As argued by Edquist [74], the notion of optimality is irrelevant in the IS approach; the innovation process develops over time in an evolutionary way and is influenced by many factors and feedback processes and an optimal system cannot be specified. Comparisons can though be made with what system developments are needed to reach specific policy targets [75].
} 
identify important challenges, such as path-dependent search processes and too strong learning networks that lead to lock-in. They can also fail to act upon poorly aligned institutions (including legitimacy), which may obstruct the formation of markets and the mobilization of resources for new technologies.

The resulting instrument mix is, thus, the outcome of a broader rationale than that associated with a static equilibrium approach. It also includes a potentially greater variety of policy instruments targeting the identified obstacles, including new, more 'systemic' instruments aiming at stimulating the build-up and continued functioning of innovation systems $[63,78]$. Policy-makers are, for example, recommended to implement instruments to induce and provide platforms for experimentation and learning (e.g. demonstration programs), raise awareness of new technologies (e.g. information campaigns), stimulate demand articulation (e.g. requirements of user involvement in $R \& D$ projects), mediate between different stakeholders (e.g. support to innovation intermediaries), reduce risks associated with large infrastructural investments (e.g. loans and guarantees) and contribute to institutional alignment within and between innovation systems (e.g. development of visions and standards) $[41,51,78]$.

In addition, since system weaknesses differ between technologies [76], policy makers are recommended to design technology-specific instrument mixes to stimulate the build-up and continued functioning of innovation systems around specific technologies [63, 78]. Rather than relying mainly on a few general instruments, such as EU ETS and competitive bidding processes for state aid, this would require them to handle a larger set of differentiated instrument mixes, targeted at each technology's specific set of weaknesses. ${ }^{8}$

Moreover, in order to deal with interdependencies between an emerging innovation system and its context, the mix might also need to include instruments targeted at overcoming system weaknesses associated with other emerging technologies - both complementary and competing (to avoid premature selection and lock-in) - or at deconstructing existing systems (e.g. performance standards or reduction of existing subsidies) [40, 51, 52, 68, 78-81].

\footnotetext{
${ }^{8}$ This set of instrument mixes could very well include instruments that are common to all (or some) technologies, such as RD\&D programs, information campaigns, feed-in tariffs or quota systems, but such instruments might need to be differentiated in terms of focus areas or support levels, depending on the specific weaknesses of the involved technologies.
} 
However, in a systems approach a suitable instrument mix is not necessarily one that includes instruments that deal with each and all weaknesses in an innovation system. The systemic and evolutionary character of the innovation process implies that any policy intervention can have far-reaching (and often unpredictable) consequences. One aspect of this is that system weaknesses may be linked in such ways that solving one fundamental weakness leads to solving others, without further interventions, while trying to solve less fundamental weaknesses without solving the core problem could lead to no effect or adverse results [82, 83]. Similarly, weaknesses might be interdependent requiring several interventions at the same time or in a specific sequence to set in motion a process of self-sustained growth. For example, R\&D support can have almost no effect without parallel market stimulation measures and capital grants to large-scale demonstration projects can fail if they are not preceded by $R \& D$ on how to up-scale a technology into functioning commercial-scale plants [84]. The overall goal for policy makers is to design instrument mixes that might trigger selfreinforcing mechanisms, allowing the system to start moving by its own momentum. Due to the uncertainties involved, this often requires frequent evaluation and re-design of the instrument mix [cf. 85].

In the following section, we will apply the system weaknesses approach and that of market failures to the case of offshore wind power in Sweden in order to illustrate the different outcomes in terms of identified obstacles to transformation and instrument mix choices.

\section{System weaknesses and market failures in off-shore wind power in Sweden $^{9}$}

Off-shore wind power is a strategic industry in the transformation of the EU electricity generation system. Indeed, in the EU Commission's [43] Vision 2050, the average supply of off-shore wind power in five decarbonisation scenarios is about $230 \mathrm{GW}$, supplying some 800 TWh per year [75]. However, current deployment is still small, but Sweden has a large potential to supply relatively cheap off-shore wind power considering that the physical conditions in the Baltic Sea are favourable compared with the North Sea. Realizing this potential may not only help replace aging Swedish nuclear power plants but, most importantly, aid the rest of EU in its efforts to replace fossil fuels.

\footnotetext{
${ }^{9}$ This section is based on Swedish Energy Agency [86] and Jacobsson et al. [87].
} 
The innovation system framework applied in this case study is that of a technological innovation system (TIS), which uses the functional concept as a tool for facilitating the identification of technology-specific system weaknesses $[61,63] .{ }^{10} \mathrm{By}$ a) analyzing the strength of the above mentioned functions in relation to a goal of 30 TWh supply in 2030-35 and b) linking weaknesses of functions to the nature of internal and external structural elements, the relevant system weaknesses were identified.

Eight system weaknesses were traced where the first three are related to institutions that obstruct market formation.

(1) The market formation policy is a tradeable green certificate system, common to all renewable electricity generation. This application of the dominant Swedish norm of technology-neutral policies [41] is designed to promote investments in currently costeffective technologies [88, p. 29] and, therefore, does not justify off-shore wind investments.

(2) This is strengthened by EU Commission's Guidelines specification that technologyspecific market formation policies shall not be granted for more than $5 \%$ of planned new electricity capacity from renewable energy sources per year, which with the large capacity of new off-shore wind farms excludes a technology-specific market formation policy. ${ }^{11}$

(3) An alternative would be to build plants with the purpose of exporting to other EU countries. National market formation policies (currently tendering systems) in the EU (e.g. Germany, UK) means, however, that Swedish export of offshore wind power need to rely on the ordinary electricity market and will, therefore, not receive cost covering prices.

Policy interventions should first focus on handling these three fundamental weaknesses. The first two, however, make it challenging to argue for, and design, a technology-specific market formation policy. A tendering system may though be chosen as it is now the dominant technology-specific instrument in EU. Introducing such a policy necessitates, however,

\footnotetext{
${ }^{10}$ For more details about the framework and the methodology, please see the sources in footnote 8 .

${ }^{11}$ In 2015, the average supply of eight offshore wind farms with permissions to build wind farms was 1.1 TWh

[87], whereas the average increase in supply of renewable electricity was 2.3 TWh in 2010-2015 [4].
} 
actions that a) improve the legitimacy of investments in currently higher cost technologies by pointing to the centrality of dynamic efficiency and by handling price-reducing effects of an increased supply of electricity that harm other important investors (e.g. those in bio-based combined heat and power plants), b) handle the interests of competing off-shore industries, such as shipping and fishing, through maritime spatial planning and c) convince the EU Commission that current Guidelines block investments that would benefit the EU. An alternative to a national tendering system would be to come to an agreement with other EU countries, e.g. Germany, to include also investments in Sweden in their tendering systems.

With a technology-specific market formation policy, more firms will be induced to enter various parts of the value chain in the system, a division of labour may develop with associated learning effects and these may be strengthened by the formation of learning networks and other sources of positive externalities (as well understood by the classical economists). Yet, a market-formation policy needs to be supplemented by policies addressing the remaining system weaknesses:

(4) The lack of differentiated technical solutions (turbines, grids etc.) appropriate for the physical conditions of the Baltic Sea (as compared with the North Sea) unduly increases costs. While market formation may stimulate a differentiation of the technology, this can be supported by an $R D \& D$ policy. This should involve both industry and academia to ensure that learning networks are formed between firms (e.g. construction companies that can develop foundations) and academia, which also needs to develop new scientific fields. With the strong links between research and education, such a policy would also strengthen the supply of the required skilled labour (see 7).

(5) Local courts sometimes have a poor knowledge base and short-term perspective when handling applications from investor to build an offshore wind farm, which stops some investments and increases uncertainties. For instance, they disregard the social value of reducing $\mathrm{CO}_{2}$ emissions through export of electricity. Government agencies therefore need to make sure that local courts have the required knowledge to understand the vision and goals for offshore wind power through an educational program.

(6) Technological and market risks result in high cost of capital, which is a serious problem in this capital intensive industry. With a differentiated market formation 
policy, investor risks would be reduced, but these policies could be supplemented with a financial policy instrument aiming at directly lowering the cost of capital.

(7) There is a shortage of specialized educational programs, which means that industry does not have access to the required human capital (e.g. electrical engineering competences). Educational policy is therefore needed, for example to encourage universities to include offshore wind power in existing and new (specialist) programs and stimulate a greater interest among students in critical programs such as electrical engineering.

(8) To keep costs down and reduce the risk that investors develop what become 'stranded assets', a coordination is needed between the location of wind farms and the development of the required grid infrastructure. There is, however, an absence of such regulations, which increases risks and costs. The regulatory framework for building grid infrastructure therefore needs to be developed and coordinated with a maritime spatial planning that allocate space for wind farms.

These eight system weaknesses would lead to a mix containing seven policy instruments. An application of the market failure approach would give a narrower perspective of the need for intervention. It would, perhaps, identify a) the need to develop technologies more appropriate for the Baltic Sea (positive externalities), b) investor risks and associated high cost of capital (capital market failure) and c) poor coordination between investments in wind farms and grids (coordination failures), but it would not label a technology-neutral market formation policy, a poor knowledge base and a short-term perspective of local courts or a lack of specialised educational programs as failures. Hence, three of eight system weaknesses would be identified and the associated instrument mix would then possibly be composed of the same instruments as identified for these three weaknesses.

\section{Concluding discussion and lessons for policy}

Limiting global warming to 1.5-2 degrees necessitates that a range of new technologies develop, mature and diffuse on a massive scale. To create conditions for this, effective instrument mixes have to be designed and implemented. In Europe, the EU Commission advocates market failures and static cost-effectiveness as guides to the selection of policy instruments, in line with a static equilibrium approach. The purpose of this paper was to scrutinize this analytical rationale, contrast it with the work of classical economists and recent 
innovation scholars, and draw lessons for how effective mixes of policy instruments may be identified.

Based in part on the heritage of the classical economists, who gave considerable attention to the industrial development processes needed to achieve transformative change, we identified weaknesses in the Commission's approach. First, while market failures capture empirical phenomena of importance to technical change they do not cover all possible obstacles. Most notably, they neglect organizational inertia and obstacles to innovation created by characteristics of networks and institutions (rather than actors and markets). The existence of such obstacles implies that market failures should not be seen as the only justification of policy interventions and that a broader instrument mix might be needed. Moreover, some phenomena (positive externalities, information asymmetries and increasing returns) that may lead to market failures are inherent features of the innovation process. A first policy lesson is, therefore a need to reflect on the relevance of the conceptual base for designing instrument mixes for transformative change.

Second, as regards market formation policy, the Commission's focus on static efficiency and technology neutrality leads it to largely neglect the centrality of dynamic efficiency. A central goal of early market formation policy should be to stimulate the generation of a range of positive externalities and foster innovative capital goods industries that facilitate the realisation of increasing returns. Indeed, for larger geographical areas, such as the EU, the development of an innovative capital goods industry is the bridge between market-forming policy and technical change as it puts a range of technologies 'on the shelf'. To achieve this, technology-specific market formation policies need to supplement neutral instruments and $a$ second policy lesson is that the scope of the former needs to be larger than what the EU Guidelines currently specify. ${ }^{12}$ Indeed, unless the Guidelines open up for a larger market space for promising but immature technologies, it is likely to lead to a weakened ability to develop the tools for combating climate change and a loss of industrialization opportunities.

The innovation system approach was identified as an alternative conceptual base. More specifically, we argued that in order to reach emission reduction goals, policy makers should

\footnotetext{
${ }^{12}$ Finding an effective balance between specific and neutral policies involves identifying when a given technology has gone far enough down its learning curve to be effectively fostered by technology-neutral instruments.
} 
aim to remedy technology-specific system weaknesses rather than market failures. The case of offshore wind power in Sweden illustrated that an innovation system approach may help identify a larger set of obstacles and justify a broader range of policy instruments than an analysis of market failures. A third policy lesson is that an innovation system approach may help EU policy makers design better instrument mixes.

A state that pursues multi-dimensional and technology-specific policy interventions is not synonymous with a planned economy but reflects an understanding of technical change and industrial dynamics that in part differs from that of the Commission. Yet, it requires a state for which it is legitimate to support desirable but immature technologies with instrument mixes that includes those stimulating market formation. This is not the same as "picking winners" but rather "fostering players", i.e. stimulating generation of a variety of alternatives that may eventually survive in a more competitive market.

However, stimulating such a variety is demanding for policy makers, since it involves many types of interventions, the design of which requires a deep understanding of industrial dynamics. Moreover, in a dynamic world, the key policy challenges change and shift character since innovation systems emerge in ways which are difficult to foresee and the effects of interventions are hard to fully anticipate. Given the experimental character of industrial dynamics, mistakes are normal elements in a learning process, in industry and in policy-making. Uncertainty is, therefore, not a reason for abstaining from interventions but rather an argument for policy-making characterized by iteration and continuous learning. $A$ fourth policy lesson is that optimising policy-makers should be replaced by adaptive policymakers [31] and that these do not only need appropriate competences and organisations to be able to design and implement useful instrument mixes but also a working environment in which mistakes are accepted as part of the transformation process.

However, while the innovation system approach is a clear conceptual alternative, the understanding of the nature of system weaknesses needs to be improved - a major task for further research. Klein Woolthuis et al. [73] summarized pioneering literature in the 1990s and substantial empirical work has taken place thereafter [cf. 76, 77], but there is still no overview of the complete range of system weaknesses - a range that can help guiding policy makers. Although the equilibrium approach is not conceptually linked to innovation systems [89], it may contribute to this, given its understanding of relevant empirical phenomena. Such 
a contribution is likely to be strengthened by relating to recent literature on dynamic, rather than static, equilibrium theory. For instance, similarly to the classical economists, Gawel et al. [17, p. 19] point to the importance of learning-by-doing and learning-by-using and argue that associated dynamic market failures justify technology-specific market formation policies. They also clarify that "ignoring the often technology-specific learning effects will lead to underinvestment in the RES-E technologies with great long-term potentials for cost reductions”. It follows that technology-specific support schemes may minimize the costs of reaching future goals, in particular through focusing on factors that influence technological development [17, 27, 42].

Gawel et al. [17, p. 19] include not only learning and capital market failures, but also path dependency, which may be reinforced by institutional factors [27]. Hence, while the dynamic equilibrium and innovation system dynamics approaches differ in their analytical bases they share key features, where the former is partly inspired by the latter [27], and both are inspired by the classical economists. It may, therefore, be valuable to apply them empirically to the same technologies to see if they, together, can help identify a complete range of system weaknesses.

\section{Acknowledgements}

We are grateful to three reviewers for their detailed reading and constructive comments.

\section{References}

[1] J. Fagerberg, S. Laestadius, B. Martin, Introduction to the triple challenge: Europe in a new age, in: J. Fagerberg, S. Laestadius, B.R. Martin (Eds.), The Triple Challenge for Europe: Economic Development, Climate Change and Governance, Oxford University Press, Oxford, 2015.

[2] Eurostat, Greenhouse gas emissions by sector, 2016. http://ec.europa.eu/eurostat/web/products-datasets/-/tsdcc210. (Accessed 9 May 2016. [3] S. Lechtenböhmer, L.J. Nilsson, M. Åhman, C. Schneider, Decarbonising the energy intensive basic materials industry through electrification - Implications for future EU electricity demand, Energy 115, Part 3 (2016) 1623-1631.

[4] IEA, Elaboration on Search statistics by country, www.iea.org/statistics, (2016).

[5] K. Flanagan, E. Uyarra, M. Laranja, Reconceptualising the 'policy mix' for innovation, Research Policy 40(5) (2011) 702-713.

[6] K.S. Rogge, K. Reichardt, Policy mixes for sustainability transitions: An extended concept and framework for analysis, Research Policy 45(8) (2016) 1620-1635.

[7] M. Howlett, J. Rayner, Patching vs Packaging in Policy Formulation: Assessing Policy Portfolio Design, Politics and Governance 1(2) (2013) 170-182. 
[8] E. Magro, J.R. Wilson, Complex innovation policy systems: Towards an evaluation mix, Research Policy 42(9) (2013) 1647-1656.

[9] C. Jägemann, A Note on the Inefficiency of Technology- and Region-Specific Renewable Energy Support: The German Case, Zeitschrift für Energiewirtschaft 38(4) (2014) 235-253. [10] A. Smith, The Wealth of Nations (reprinted in 1977), Penguin Books, London, 1776.

[11] A. Marshall, Principles of Economics (8th Ed.) (reprinted in 1962), Macmillan \& Co., London, 1890/1920.

[12] J. Fagerberg, Innovation policy: rationales, lessons and challenges, Journal of Economic Surveys 31(2) (2017) 497-512.

[13] P. Stoneman, The Economic Analysis of Technology Policy, Clarendon Press, Oxford, 1987.

[14] European Commission, Communication from the Commission - Guidelines on State aid for environmental protetion and energy for 2014-2020., Official Journal of the European Union C 200/01, 28.6 .2014 (2014) 1-55.

[15] P. Barbaroux, From market failures to market opportunities: managing innovation under asymmetric information, Journal of Innovation and Entrepreneurship 3(1) (2014) 5.

[16] W.H. Corden, Trade Policy and Economic Welfare, Oxford University Press, Oxford, 1974.

[17] E. Gawel, P. Lehmann, A. Purkus, P. Söderholm, K. Witte, Rationales for technologyspecific RES support and their relevance for German policy, Energy Policy 102 (2017) 16-26. [18] European Commission, Communication from the Commission to the European Parliament, the Council, the European Economic and Social Committee and the Committee of the regions - Energy Technologies and Innovation, COM(2013) 253 final 2.5.2013 (2013). [19] European Commission, Communication from the Commission - Towards an Integrated Strategic Energy Technology (SET) Plan: Accelerating the European Energy System Transformation, C(2015) 6317 final 15.9.2015 (2015).

[20] European Commission, Commission staff working document, Impact Assessment accompanying the document 'Guidelines on State aid for environmental protection on energy for 2014-2020’ European Commission, Brussels, 2014.

[21] European Commission, Electricity from Renewable Energy Sources and the Internal Electricity market, Commission Working Paper, SEC (99) 470, 13 April 1999., 1999.

[22] V. Lauber, E. Schenner, The struggle over support schemes for renewable electricity in the European Union: a discursive-institutionalist analysis, Environmental Politics 20(4) (2011) 508-527.

[23] European Commission, Commission regulation (EU) No 651/2014 of 17 June 2014 declaring certain categories of aid compatible with the internal market in application of Articles 107 and 198 of the Treaty, Official Journal of the European Union L 187, 26.6.2014 (2014) 1-78.

[24] P. Lehmann, Justifying a policy mix for pollution control: a review of economic literature, Journal of Economic Surveys 26(1) (2012) 71-97.

[25] P. del Río, Why does the combination of the European Union Emissions Trading Scheme and a renewable energy target makes economic sense?, Renewable and Sustainable Energy Reviews 74 (2017) 824-834.

[26] P. Lehmann, E. Gawel, Why should support schemes for renewable electricity complement the EU emissions trading scheme?, Energy Policy 52 (2013) 597-607.

[27] P. Lehmann, P. Söderholm, Can technology-specific deployment policies be costeffective? The case of renewable energy support schemes, in: U.D.P.N. 1/2016 (Ed.) 2016. [28] W.R. Scott, Adam Smith as Student and Professor, Jackson, Son \& Company, Glasgow, 1937.

[29] K. Marx, Capital, Vol 1 (reprinted in 1974), Lawrence \& Wishart, London, 1887. 
[30] A.A. Young, Increasing Returns and Economic Progress, The Economic Journal 38(152) (1928) 527-542.

[31] J.S. Metcalfe, Technology systems and technology policy in an evolutionary framework, Cambridge Journal of Economics 19(1) (1995) 25-46.

[32] J.S. Metcalfe, System failure and the case for innovation policy, in: P. Llerena, M. Matt (Eds.), Innovation policy in a knowledge-based economy, Springer, Berlin, 2005, pp. 47-74.

[33] B. Carlsson, S. Jacobsson, Technological systems and industrial dynamics, in: E.

Helmstädter, M. Perlman (Eds.), Behavioral Norms, Technological Progress and Ecnomic Dynamics, University of Michigan Press, Ann Arbor, 1996.

[34] K. Onufrey, A. Bergek, Self-reinforcing Mechanisms in a Multi-technology Industry: Understanding Sustained Technological Variety in a Context of Path Dependency, Industry and Innovation 22(6) (2015) 523-551.

[35] P. del Río, On evaluating success in complex policy mixes: the case of renewable energy support schemes, Policy Sciences 47(3) (2014) 267-287.

[36] A. Bergek, S. Jacobsson, The Emergence of a Growth Industry: A Comparative Analysis of the German, Dutch and Swedish Wind Turbine Industries, in: S. Metcalfe, U. Cantner (Eds.), Change, Transformation and Development, Physica-Verlag, Heidelberg, 2003, pp. 197-227.

[37] C. Cooper, Policy intervention for technological innovation in less-developed countries, Science Policy Research Unit, Sussex University, Falmer, 1976.

[38] A. Lundgren, Technological Innovation and Industrial Evolution - the emergence of industrial networks, The Economic Research Institute, Stockholm School of Economics, Stockholm, 1991.

[39] S. Jacobsson, B.A. Sandén, L. Bångens, Transforming the energy system-the evolution of the German technological system for solar cells, Technology Analysis and Strategic Management 16(1) (2004) 3-30.

[40] B.A. Sandén, C. Azar, Near-term technology policy for long-term climate targets economy wide versus technology specific approaches, Energy Policy 33(12) (2005) 15571576.

[41] C. Azar, B.A. Sandén, The elusive quest for technology-neutral policies, Environmental Innovation and Societal Transitions 1(1) (2011) 135-139.

[42] B.A. Sandén, The economic and institutional rationale of PV subsidies., Solar Energy, 78 (2005) 137-146.

[43] European Commission, European Commission (2011): Energy Roadmap 2050:

Commission Staff Working Paper, Impact Assessment. SEC 2011, 1565. , European

Commission, Brussels, 2011.

[44] I. Pineda, P. Tardieu, The European offshore wind industry. Key trends and statistics 2016, WindEurope, Brussels, 2017.

[45] M. Dodgson, A. Hughes, J. Foster, S. Metcalfe, Systems thinking, market failure, and the development of innovation policy: The case of Australia, Research Policy 40(9) (2011) 11451156.

[46] B. Carlsson, R. Stankiewicz, On the nature, function and composition of technological systems, Journal of Evolutionary Economics 1(2) (1991) 93-118.

[47] C. Freeman, The 'National System of Innovation' in historical perspective, Cambridge Journal of Economics (19) (1995) 5-24.

[48] B.-Å. Lundvall, National Systems of Innovation - toward a Theory of Innovation and Interactive Learning, Pinter Publishers, London, 1992.

[49] F. Malerba, Sectoral systems of innovation and production, Research Policy 31(2) (2002) 247-264. 
[50] J.S. Metcalfe, Evolutionary Economics and Technology Policy, The Economic Journal 104(425) (1994) 931-944.

[51] S. Jacobsson, A. Bergek, Transforming the energy sector: the evolution of technological systems in renewable energy technology, Industrial and Corporate Change 13(5) (2004) 815849.

[52] A. Bergek, S. Jacobsson, B.A. Sandén, 'Legitimation' and 'development of positive externalities': Two key processes in the formation phase of technological innovation systems, Technology Analysis and Strategic Management 20(5) (2008) 575-592.

[53] J.S. Metcalfe, Equilibrium and evolutionary foundations of competition and technology policy: new perspectives on the division of labour and the innovation process, Revista Brasileira de Inovação 2(1) (2003) 111-146.

[54] M. Fransman, The Market and Beyond, Cambridge University Press, Cambridge, 1990. [55] P.A. David, Clio and the Economics of QWERTY, The American Economic Review 75(2) (1985) 332-337.

[56] M. Tripsas, G. Gavetti, Capabilities, cognition, and inertia: evidence from digital imaging, Strategic Management Journal 21(10-11) (2000) 1147-1161.

[57] H.I. Ansoff, E.J. McDonnell, Implanting Strategic Management (2nd Ed.), Prentice Hall, Cambridge, 1990.

[58] B.-Å. Lundvall, Innovation as an interactive process: from user-supplier interaction to the National System of Innovation, in: G. Dosi, C. Freeman, R. Nelson, G. Silverberg, L. Soete (Eds.), Technical Change and Economic Theory, Francis Pinter, London, 1988.

[59] O. Gassmann, E. Enkel, H. Chesbrough, The future of open innovation, R\&D Management 40(3) (2010) 213-221.

[60] W.R. Scott, Institutions and Organizations, Sage Publications, Thousand Oaks, 1995. [61] A. Bergek, S. Jacobsson, B. Carlsson, S. Lindmark, A. Rickne, Analyzing the functional dynamics of technological innovation systems: A scheme of analysis, Research Policy 37(3) (2008) 407-429.

[62] S. Kline, and, N. Rosenberg, An Overview of Innovation, in: R. Landau, and, N. Rosenberg (Eds.), The Positive Sum Strategy, National Academy Press, Washington D.C., 1986, pp. 275-305.

[63] A. Bergek, S. Jacobsson, M. Hekkert, K. Smith, Functionality of innovation systems as a rationale and guide in innovation policy, in: R. Smits, S. Kuhlmann, P. Shapira (Eds.), The Theory and Practice of Innovation Policy, Edward Elgar, Cheltenham,, 2010, pp. 117-146. [64] A. Bergek, M. Hekkert, S. Jacobsson, J. Markard, B. Sandén, B. Truffer, Technological innovation systems in contexts: Conceptualizing contextual structures and interaction dynamics, Environmental Innovation and Societal Transitions 16 (2015) 51-64.

[65] G. Myrdal, Economic theory and underdeveloped regions, Ducksworth, London, 1957.

[66] C. Wilson, Up-scaling, formative phases, and learning in the historical diffusion of energy technologies, Energy Policy 50 (2012) 81-94.

[67] S. Borrás, C. Edquist, The choice of innovation policy instruments, Technological Forecasting and Social Change 80(8) (2013) 1513-1522.

[68] K.M. Weber, H. Rohracher, Legitimizing research, technology and innovation policies for transformative change: Combining insights from innovation systems and multi-level perspective in a comprehensive 'failures' framework, Research Policy 41(6) (2012) 10371047.

[69] N. Sharif, Emergence and development of the National Innovation Systems concept, Research Policy 35(5) (2006) 745-766.

[70] K. Smith, Innovation as a Systemic Phenomenon: Rethinking the Role of Policy, Enterprise \& Innovation Management Studies 1(1) (2000) 73-102. 
[71] K. Smith, Systems Approaches to Innovation: Some Policy Issues, STEP Group, Oslo, 1996.

[72] B. Carlsson, and, S. Jacobsson, In search of useful public policies - key lessons and issues for policy makers, in: B. Carlsson (Ed.), Technological Systems and Industrial Dynamics, Kluwer Academic Publishers, Dordrecht, 1997, pp. 299-315.

[73] R. Klein Woolthuis, M. Lankhuizen, V. Gilsing, A system failure framework for innovation policy design, Technovation 25(6) (2005) 609-619.

[74] C. Edquist, Systems of innovation. Perspectives and challenges., in: J. Fagerberg, D.C. Mowery (Eds.), The Oxford Handbook of Innovation, Oxford University Press, Oxford, 2006, pp. 181-208.

[75] S. Jacobsson, K. Karltorp, Mechanisms blocking the dynamics of the European offshore wind energy innovation system - Challenges for policy intervention, Energy Policy 63(0) (2013) 1182-1195.

[76] S. Jacobsson, A. Bergek, Innovation system analyses and sustainability transitions: Contributions and suggestions for research, Environmental Innovation and Societal Transitions 1(1) (2011) 41-57.

[77] A.J. Wieczorek, M.P. Hekkert, Systemic instruments for systemic innovation problems: A framework for policy makers and innovation scholars, Science and Public Policy 39(1) (2012) 74-87.

[78] R. Smits, S. Kuhlmann, The rise of systematic instruments in innovation policy, Int. J. Foresight and Innovation Policy 1(1/2) (2004) 4-32.

[79] B.A. Sandén, K.M. Hillman, A framework for analysis of multi-mode interaction among technologies with examples from the history of alternative transport fuels in Sweden, Research Policy 40(3) (2011) 403-414.

[80] T. Meelen, J. Farla, Towards an integrated framework for analysing sustainable innovation policy, Technology Analysis \& Strategic Management 25(8) (2013) 957-970. [81] P. Kivimaa, F. Kern, Creative destruction or mere niche support? Innovation policy mixes for sustainability transitions, Research Policy 45(1) (2016) 205-217.

[82] J. Andersson, E. Perez Vico, L. Hammar, B.A. Sandén, The critical role of informed political direction for advancing technology: The case of Swedish marine energy, Energy Policy 101 (2017) 52-64.

[83] A. Kieft, R. Harmsen, M.P. Hekkert, Interactions between systemic problems in innovation systems: The case of energy-efficient houses in the Netherlands, Environmental Innovation and Societal Transitions (in press).

[84] B.A. Sandén, S. Jacobsson, Teknikpolitiska lärdomar, in: H. Hellsmark (Ed.), Teknologiska innovationssystem inom energiområdet. En praktisk vägledning till identifiering av systemsvagheter som motiverar särskilda politiska åtaganden, ER 2014:23, Statens energimyndighet, Eskilstuna, 2014, pp. 261-286.

[85] C.E. Lindblom, The Science of "Muddling Through", Public Administration Review 19(2) (1959) 79-88.

[86] Swedish Energy Agency, Teknologiska innovationssystem inom energiområdet. En praktisk vägledning till identifiering av systemsvagheter som motiverar särskilda politiska åtaganden, Swedish Energy Agency, Eskilstuna, 2014.

[87] S. Jacobsson, F. Dolff, K. Karltorp, Bidrag till handlingsplan för havsbaserad vindkraft i Sverige, Environmental Systems Analysis, Department of Energy and Environment, Chalmers University of Technology, Göteborg, 2015.

[88] Swedish Government, Förnybar el med gröna certifikat ("Renewable electricity with green certificates”), Government Bill (prop. 2005/06:154), 22 March 2006, Stockholm., 2006. [89] M. Bleda, P. del Río, The market failure and the systemic failure rationales in technological innovation systems, Research Policy 42(5) (2013) 1039-1052. 
